\title{
RESEARCH ON ATOMIZING MICRO-CLIMATE REGULATION TECHNOLOGIES FOR VINEYARDS IN EXTREMELY ARID AREAS IN SHANSHAN COUNTY, CHINA
}

\author{
YANG, S. ${ }^{1,4}-\mathrm{BAI}, \mathrm{Y}^{2^{*}}-\mathrm{YANG} \mathrm{T}^{1,3}$ \\ ${ }^{1}$ State Key Laboratory of Desert and Oasis Ecology, Xinjiang Institute of Ecology and \\ Geography, Chinese Academy of Sciences, 830011 Urumqi, China \\ ${ }^{2}$ Xinjiang Institute of Water Resources and Hydropower Research, 830049 Urumqi, China \\ ${ }^{3}$ State Key Laboratory of Hydrology Water Resources and Hydraulic Engineering, Hohai \\ University, Nanjing, 210098 Jiangsu, China \\ ${ }^{4}$ University of Chinese Academy of Sciences, 100101 Beijing, China \\ *Corresponding author \\ e-mail:xjbaiyg@sina.com; phone: +86-99-1852-3145 \\ (Received $1^{\text {st }}$ Jun 2019; accepted $2^{\text {nd }}$ Sep 2019)
}

\begin{abstract}
In response to characteristics of the natural climate in extremely arid areas and the physiological characteristics of grapes in Shanshan County, China, and by relying on micro-spray atomizing regulation technology to change micro-climate environments in vineyards and using methods of contrastive analysis of test data and model calculation analysis, this paper studies changes in grape physiological ecology, photosynthetic characteristics, quality and yield under atomizing regulation action and proposes an optimal technical scheme for atomizing regulation: the atomizing regulation treatment can lower average temperatures by $1.6^{\circ} \mathrm{C}$ during grape expansion periods, increase average humidity by $6.6 \%$, and improve grape branch length, internode length, leaf number, leaf area, mid-rib length and ovendry weight better than conventional drip irrigation (CK) treatment. Fitting calculation analysis of the photosynthetic rate, $\mathrm{CO}_{2}$ concentration response curve, and light response curve through a mathematical model shows that the atomizing regulation treatment has less influence on photosynthetic characteristics of grapes but helps improve grape quality and provides higher yield than conventional drip irrigation (CK) treatment. Spray water for $1 \mathrm{~h}$ a day (WP2) treatment creates optimal quality and the highest yield, $24.0 \%$ higher than that of conventional drip irrigation (CK) treatment. All research data indicate that spray water for $1 \mathrm{~h}$ a day (WP2) treatment is an optimal technical scheme for atomizing regulation treatment of vineyards in extremely arid areas and creates strong benefits, including a high water resource utilization ratio, enhancement of micro-climates, obvious quality improvement, and yield increase effects. Keywords: vineyard, micro-spray atomization, micro-climate physiological ecology, photosynthesis, yield, quality
\end{abstract}

\section{Introduction}

The Turpan-Hami and Rim-Tarim Basins in Xinjiang enjoy light, heat, water and soil conditions suitable for grape growing, with a wide variety of grapes and high grape quality, thus serving as the main sources of grapes in China (Liu et al., 2019). However, the region is characterized by sparse precipitation, strong evaporation, heavy sandstorms, high temperatures and hot weather during the summer, with the highest temperature in daylight at over $40^{\circ} \mathrm{C}$. Such extreme natural climate conditions heavily influence grape quality and yields. At present, traditional irrigation technology can only address basic water demands for grape growth but cannot fundamentally change climate factors that influence grape quality and yield. For this reason, this research proposes micro-spray 
atomizing regulation technology for vineyards in extremely arid areas to address the issue of micro-climates using the following principle: keeping traditional modes of irrigation, arrange micro-spray heads at different positions in the grape trellis and control the length of spraying time and cycle for each water head, to form new artificial microclimates in the vineyard and research changes in physiological ecology, photosynthetic characteristics, and quality and yield of grapes under the effects of artificial microclimate-influencing factors.

Currently, more attention has been paid to micro-spray atomizing regulation technology by researchers, and some technical studies have been carried out both in China and abroad. For example, a study by Zhang et al. (2000) found that the conditions of active, accumulated temperatures $\geq 10^{\circ} \mathrm{C}$ are highly related to grape characteristics during the mature period. Chen et al. (1996) has analyzed the agricultural, meteorological effect of mulberry field spray irrigation and drew the conclusion that micro-spray irrigation makes daylight average water vapor pressure increase by $1.33-1.73 \mathrm{hPa}$, makes humidity increase by $4-8 \%$, and enhances moisture production efficiency by 10-49\%. Liu et al. (2000) researched the influence of micro-spray on wheat field microclimates and found that micro-spray irrigation can influence canopy air temperature and humidity during irrigation and that there are phenomena of increasing inversion times, drops in temperature, and increases in humidity over the canopy. Bai et al. (2016a) researched the influence of micro-spray atomizing regulation irrigation technology on grape physiology and yield and found that this technology can produce high grape yields when the irrigation norm is 9,150 $\mathrm{m}^{3} / \mathrm{hm}^{2}$ and water is sprayed $1-2 \mathrm{~h}$ once a day at a spraying capacity of $105-120 \mathrm{~m}^{3} / \mathrm{hm}^{2}$ per spray. Koblet addressed the influence of light and temperature on vine performance in cool climates and its application to vineyard management in proceedings of an international symposium on cool climate vatic and enol (Koblet, 1986). Jackson examined aspects of light conditions in apple orchards (Jackson, 1970). Kohl et al. assessed the measurement of low pressure sprinkler poration (Kohl et al., 1987). Srinivas et al. (2000) carried out studies on grape growth and development, as well as moisture utilization efficiency, under different irrigation modes, such as drip irrigation and alternative root area irrigation. Studies by Hui et al. (2007) on main grape physiological indicators of water stress show that under water stress, grape leaf compositions of free proline and malondialdehyde increase with a rise in stress level. Under the influence of hightemperature stress, grape seedlings have a mechanism for quick heat resistance in a short period of time. Temperature has a clear influence on group photosynthesis of Kyoho grapes; high temperatures reduce the initial photochemistry efficiency, but increases maximize photosynthetic rates in Kyoho grapes under low $\mathrm{CO}_{2}$ concentrations (Xie et al., 1998, 2007; Tang et al., 2006). However, studies on how climate factors in extremely arid areas influence grape physiological ecology, photosynthetic characteristics, quality and quantity are still insufficient. Some key problems remain unsolved, and field management still lacks effective technical support. Therefore, it is of great practical significance to promote comprehensive, harmonious and sustainable development of both society and the economy; research and propose a technical scheme of micro-spray atomizing regulation for grape growth; monitor various grape physiological, ecological indicators under different micro-climate conditions; analyze the relationship between different microclimate environments and their influences on photosynthetic characteristics, quality, and yield of grapes in extremely arid areas; and explore an optimal technical scheme for atomizing regulation to improve moisture production efficiency, solve problems associated with grape quality improvement, and increase grape yields in extremely arid areas. 


\section{Study area}

The study area is in the test base of Xinjiang Shanshan Grape, Fruit and Melon Development and Research Center, $42.91^{\circ} \mathrm{N}, 90.30^{\circ} \mathrm{E}, 419 \mathrm{~m}$ above sea level, a soil type of gravel sandy loam, an average annual rainfall of $25.3 \mathrm{~mm}$, an average annual evaporationpan evaporation of $2,751 \mathrm{~mm}$, yearly sunshine time of $3,122.8 \mathrm{~h}$, a higher-than- $10{ }^{\circ} \mathrm{C}$ effective accumulated temperature more than $4,525^{\circ} \mathrm{C}$, and a frost-free period of up to 192 $\mathrm{d}$, all features belonging to a typical, extremely arid climate. In the study area, the variety of seedless white grapes is ideal for relevant research. The vine was planted in 1981 in trenches along the east-west run, which is $54 \mathrm{~m}$ long, 1.0-1.2 m wide, and $0.5 \mathrm{~m}$ deep; the row spacing is approximately $1.2-1.5 \mathrm{~m}$ with a row pitch of $3.5 \mathrm{~m}$; the cultivation mode is small-trellis cultivation, with the trellis front end at $1.5 \mathrm{~m}$ high and the rear end at $0.8 \mathrm{~m}$ high. The experiment was conducted from May 2016 to September 2016.

\section{Data and research methodology}

\section{Atomization treatment design}

The atomizing regulation test is designed with 7 treatments in total, each of which is arranged with 2 repeats. Each test block has an area of approximately $207 \mathrm{~m}^{2}$. Micro-spray heads are arranged at $50 \mathrm{~cm}$ over the trellis (WP1), $50 \mathrm{~cm}$ under the trellis (WP2), and 30 $\mathrm{cm}$ above the ground (WP3). In addition, at $50 \mathrm{~cm}$ under the trellis, there are three additional treatments with different water spraying time lengths and cycles, namely, WP4, WP5 and WP6. Micro sprinkler working pressure $0.3 \mathrm{mpa}$ (30 $\mathrm{m}$ water head), all treatments have a spray diameter of $200 \mathrm{~cm}$, the sprinkler spacing is $200 \mathrm{~cm}$, a flow of $40 \mathrm{~L} / \mathrm{h}$, It opens at 12:00 a.m. during the period of grape expansion (May 29, 2016 - July 4, 2016). CK treatment is a traditional treatment lacking micro-spray facilities. The irrigation norm is the total water consumption of grapes within a single mist-spraying growth cycle. The experiment scheme is shown in Table 1.

Table 1. Micro-spray treatment design parameters

\begin{tabular}{|c|c|c|c|c|c|c|c|}
\hline \multirow{2}{*}{$\begin{array}{c}\text { Test } \\
\text { treatment }\end{array}$} & \multirow{2}{*}{$\begin{array}{c}\text { Irrigation } \\
\text { water } \\
\text { volume }\left(\mathbf{m}^{\mathbf{3}}\right)\end{array}$} & \multirow{2}{*}{$\begin{array}{l}\text { Irrigation } \\
\text { norm }\left(\mathbf{m}^{\mathbf{3}}\right)\end{array}$} & \multirow{2}{*}{$\begin{array}{l}\text { Mist spraying } \\
\text { time length (h) }\end{array}$} & \multirow{2}{*}{$\begin{array}{l}\text { Mist spraying } \\
\text { cycle (day) }\end{array}$} & \multirow{2}{*}{$\begin{array}{l}\text { Micro-spray } \\
\text { arrangement mode }\end{array}$} & \multicolumn{2}{|c|}{$\begin{array}{c}\text { Micro-spray head } \\
\text { parameters }\end{array}$} \\
\hline & & & & & & $\begin{array}{c}\text { Spray head } \\
\text { flow }(\mathrm{L} / \mathrm{h})\end{array}$ & \begin{tabular}{|c} 
Spray \\
diameter $(\mathrm{cm})$
\end{tabular} \\
\hline WP1 & 30 & 610 & 1 & Every day & $50 \mathrm{~cm}$ over the trellis & \multirow{7}{*}{40} & \multirow{7}{*}{200} \\
\hline WP2 & 30 & 610 & 1 & Every day & $50 \mathrm{~cm}$ under the trellis & & \\
\hline WP3 & 30 & 610 & 1 & Every day & $30 \mathrm{~cm}$ above the ground & & \\
\hline WP4 & 60 & 1220 & 2 & Every day & \multirow{4}{*}{$50 \mathrm{~cm}$ under the trellis } & & \\
\hline WP5 & 90 & 1830 & 3 & Every day & & & \\
\hline WP6 & 60 & 610 & 2 & Once every 1 day & & & \\
\hline WP7 & 90 & 610 & 3 & Once every 2 days & & & \\
\hline CK & $*$ & 610 & $*$ & $*$ & $*$ & $*$ & $*$ \\
\hline
\end{tabular}

\section{Data measurement}

\section{Photosynthetic data measurement}

On July 1, 2016 (early stage of fruit development), three leaves were selected from each treated vine and vine. From 8:00 a.m. to 20:00 p.m., a portable photosynthetic 
system CIRAS-3 (PP SYSTEMS, USA) was used to measure photosynthetic data of selected leaves of sample trees every $2 \mathrm{~h}$. A total of 7 groups of data were measured in one day. Mean values of photosynthetic data of three leaves were measured at the same time as photosynthetic data at that time.

\section{Measurement of temperature and humidity under 2.2.2 rattan}

Under each scaffold, a set of louvers were installed at 10, 20, 30, 40 and $50 \mathrm{~cm}$ above the surface, totaling 5 groups. Three groups of HC-2 automatic temperature and humidity recorders were built into each louver to monitor the air temperature and humidity under the scaffold, and the recording interval was $30 \mathrm{~min}$.

\section{Determination of yield and quality}

Determination of grape quality: 20 clusters of ears were randomly selected from each treatment, 3 grains were randomly selected from the selected ears, and the content of soluble solids was determined by hand-held refractometer; the content of soluble sugar was determined by anthrone colorimetry; the total acid content was determined by $\mathrm{NaOH}$ titration. Tartaric acid, 2,6-dichloroindophenol titration for reducing Vc, sugaracid ratio: soluble sugar content/total acid content.

During grape harvesting, all the ears in the same treatment were weighed and the total yield was calculated: the total fruit quality in this treatment/the area occupied by the treatment experimental field (hectare).

\section{Determination of physiological indicators in vineyards}

During the period of grape germination and leaf development, three sample trees with good growth were selected from each treatment, three branches were selected from each sample tree and marked. From May 6 to June 15, the branch growth was measured once every 7 days with a tape measure of $1 \mathrm{~mm}$ accuracy. The length of each node, the number of leaves per branch were recorded, and one branch was selected from the selected branches. A vernier caliper with an accuracy of $0.01 \mathrm{~mm}$ was used to measure and record the length of the marker veins. The formula for calculating the leaf area of grape branches is as follows: leaf area $=1.183 * \mathrm{X} 0.456 * \mathrm{~N}$, where $\mathrm{X}$ is the midrib length of leaves and $\mathrm{N}$ is the number of leaves.

During the germination period, a fixed number of new branches of grapevine were selected and marked to avoid pruning of the marked branches. Starting from May 11, 2016, three branches were selected from each treatment every 10 days or so, and then cut from the new parts and put into the corresponding breathable paper bags, using the one set at $85{ }^{\circ} \mathrm{C}$. The oven is baked for $24 \mathrm{~h}$. After natural cooling, the electronic balance with accuracy of $0.1 \mathrm{~g}$ is weighed and recorded.

\section{Mathematical model}

This research adopts fitted values and actual, measured values of four mathematical models for contrastive analysis, namely, "rectangular hyperbola model (Society et al., 1935), non-rectangular hyperbola model (Thornley et al., 1976), exponential function model (Ye, 2010) and corrected rectangular hyperbola model (Liao et al., 2012)", with Four kinds of mathematical models simulate the changes of photosynthetic characteristics of CK treatment in vineyard, and compare the simulated values with the 
measured values. The purpose is to screen out more suitable models for simulating the photosynthetic characteristics of the region from many different models. On this basis, the selected models are used to simulate the changes of photosynthetic characteristics under different conditions. It can reduce some repetitive tests and improve work efficiency.

\section{CO2 response curve calculation method}

Set effective light radiation intensity $(\mathrm{PAR})$ at $1,200 \mu \mathrm{mol} \cdot \mathrm{m}^{-2} \cdot \mathrm{s}^{-1}$ and set reference lab $\mathrm{CO}_{2}$ concentrations at 50,100, 150, 200, 400, 600, 800, 1000, 1200, 1400, 1600 and $1800 \mu \mathrm{mol} / \mathrm{mol}$ to carry out two repetitive determinations. The $\mathrm{CO}_{2}$ response curve fitting equation is the same as the light response curve, and the rectangular hyperbola model is adopted for fitting, namely:

$$
A=\frac{\alpha A_{\max } C_{i}}{\alpha C_{i}+A_{\max }}-R_{p}
$$

where $\alpha$ is the initial carboxylation efficiency, $C_{i \mathrm{i}}$ is the intercellular $\mathrm{CO}_{2}$ concentration, and $R_{p}$ is the light respiration rate.

The fitting formula of the $\mathrm{CO}_{2}$ concentration saturation point (CSP) and $\mathrm{CO}_{2}$ concentration compensation point $(\mathrm{CCP})$ is:

$$
A=a C_{i}-R_{p}\left(C_{i} \leq 200 \mathrm{umol} \cdot \mathrm{mol} / \mathrm{mol}\right)
$$

where, when $A=0, C_{i}$ is the $\mathrm{CO}_{2}$ concentration compensation point (CCP); when $A=A_{\max }, C_{i}$ is the $\mathrm{CO}_{2}$ concentration saturation point (CSP); and the initial carboxylation efficiency $(\alpha)$ is expressed as the slope at the initial, straight-line section when $\mathrm{CO}_{2}$ concentration is under $200 \mu \mathrm{mol} / \mathrm{mol}$ in the $\mathrm{CO}_{2}$ response curve.

\section{Light response curve calculation method}

Set the temperature at $(25 \pm 1){ }^{\circ} \mathrm{C}$ and the relative air humidity $(\mathrm{RH})$ at $60-70 \%$; use the Model CIRAS-3 portable photosynthesis meter to determine the light response curve and $\mathrm{CO}_{2}$ response curve by controlling light and $\mathrm{CO}_{2}$ concentrations. In determining the light response curve, diurnal variation of photosynthesis was selected for the measured leaves. the $\mathrm{CO}_{2}$ concentration is set at $400 \mu \mathrm{mol} / \mathrm{mol}$, and the intensity of illumination is set at $0,50,100,150,200,300,400,600,800,1000,1200,1400,1600,1800$ and $2000 \mu \mathrm{mol} \cdot \mathrm{m}^{-2} \cdot \mathrm{s}^{-1}$.

\section{Results}

\section{Influence of atomizing regulation technology on vineyard microclimate changes}

\section{Temperature change under the trellis}

(1) Monthly temperature change: The monthly average temperature is obtained from the daily temperature of the same month. The temperature of micro-spraying treatment is the average temperature of all micro-spraying treatments. The control treatment is the monthly average temperature of $\mathrm{CK}$ treatment. As shown in Figure 1, during the grape 
expansion period (June - Aug.), atomizing regulation technology can significantly lower the temperature under the vineyard trellis and improve vineyard microclimates compared with CK treatment, with drops in temperature of $1.5,1.7$ and $1.5{ }^{\circ} \mathrm{C}$ in June, July and August, respectively, an average drop in temperature of $1.6^{\circ} \mathrm{C}$, and a drop range of $5.6 \%$.

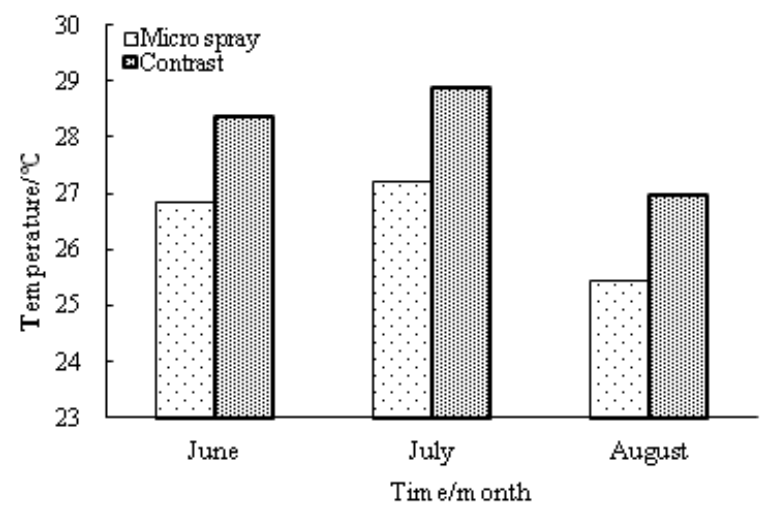

Figure 1. Monthly temperature change

(2) Daily temperature change: Daily temperature is obtained from every $30 \mathrm{~min}$ recorded by air thermometer and hygrometer during the period of micro-spraying during fruit swelling. As shown in Table 2, atomizing regulation treatment produces a daily highest temperature and daily lowest temperature $1.4{ }^{\circ} \mathrm{C}$ and $0.4{ }^{\circ} \mathrm{C}$ lower than those of CK treatment, respectively, during the grape expansion period. WP1, WP2, WP3, WP4, WP5, WP6, and WP7 daily average temperatures are 27.4, 27.6, 27.3, 27.6, 27.2, 27.4, and $27.4{ }^{\circ} \mathrm{C}$ respectively, which, on average, are $0.9{ }^{\circ} \mathrm{C}$ lower than the $\mathrm{CK}$ treatment average of $28.3^{\circ} \mathrm{C}$.

Table 2. Temperature change

\begin{tabular}{c|c|c}
\hline \multirow{2}{*}{ Treatment } & \multicolumn{2}{|c}{ Temperature $\left({ }^{\circ} \mathbf{C}\right)$} \\
\cline { 2 - 3 } & Max value & Min value \\
\hline WP1 & 33.1 & 21.6 \\
WP2 & 33.7 & 21.5 \\
WP3 & 33.0 & 21.6 \\
WP4 & 33.3 & 21.8 \\
WP5 & 32.7 & 21.8 \\
WP6 & 33.1 & 21.7 \\
WP7 & 33.2 & 21.6 \\
CK & 34.6 & 22.0 \\
\hline
\end{tabular}

\section{Humidity change under the trellis}

(1) Monthly humidity change: The monthly average humidity is obtained from the daily humidity of that month. The humidity of micro-spraying treatment is the average humidity of all micro-spraying treatments. The control treatment is the monthly average 
humidity of $\mathrm{CK}$ treatment. As shown in Figure 2, atomizing regulation treatment produces humidity increases by 5, 7.4 and $7.3 \%$ in June, July and August, respectively, with an average humidity increase of $6.6 \%$ and a range of increase of $13.8 \%$.

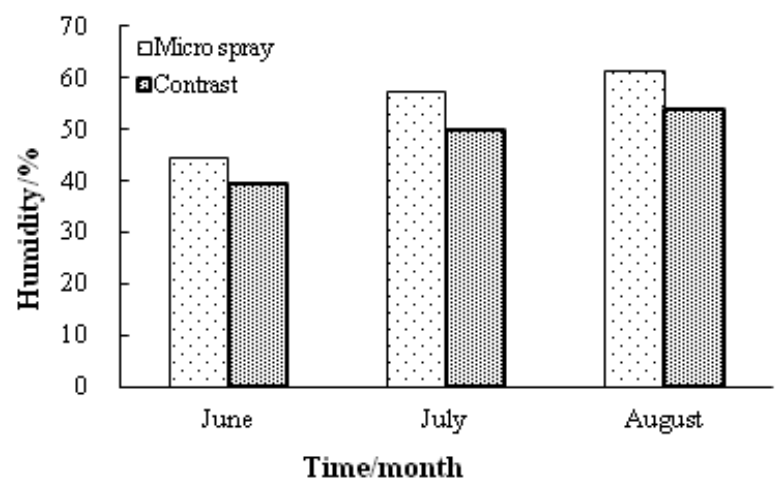

Figure 2. Monthly humidity change

(2) Daily humidity change: Daily humidity is the value of humidity every $30 \mathrm{~min}$ recorded by air thermometer and hygrometer during fruit expanding period. As shown in Table 3, atomizing regulation treatment produces a daily highest humidity and daily lowest humidity $3.0 \%$ and $1.0 \%$ higher than those of CK treatment, respectively, in June - August. Average daily humidity levels of WP1, WP2, WP3, WP4, WP5, WP6, and WP7 are 57.0, 60.4, 59.6, 57.4, 58.0, 58.3, and 59.6\%, respectively, which, on average, are $15.9 \%$ higher than the $\mathrm{CK}$ treatment average of $56.6^{\circ} \mathrm{C}$.

Table 3. Daily humidity change

\begin{tabular}{c|c|c}
\hline \multirow{2}{*}{ Treatment } & \multicolumn{2}{|c}{ Humidity (\%) } \\
\cline { 2 - 3 } & Max. value & Min. value \\
\hline WP1 & 84.9 & 29.1 \\
WP2 & 91.5 & 29.3 \\
WP3 & 89.7 & 29.5 \\
WP4 & 85.0 & 29.8 \\
WP5 & 86.3 & 29.8 \\
WP6 & 86.2 & 30.5 \\
WP7 & 88.3 & 30.9 \\
CK & 84.4 & 28.9 \\
\hline
\end{tabular}

\section{Influence of atomizing regulation treatment on changes in grape physiological ecology}

Change in vine branch length

Length of vine branch under various atomization treatments is shown in Figure 3, which shows that the vine branch length continued to increase from May 6 to June 15 and that by Sept. 1, the grape harvesting time, the average vine branch lengths under WP1, WP2, WP3, WP4, WP5, WP6, WP7 and CK treatments were 58.3, 79.7, 79.7, $58.9,55.5,60.3,79.8$ and $58.0 \mathrm{~cm}$, respectively. 


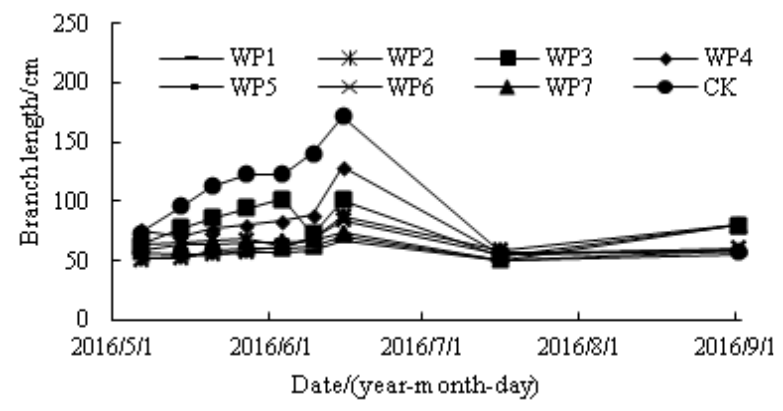

Figure 3. Change in branch length

Change in vine internode length

Changes in vine internode length under atomization treatment are shown in Figure 4, which shows that vine internode length continued to increase from May 6 to June 15 and that by Sept. 1, the average internode lengths under WP1, WP2, WP3, WP4, WP5, WP6, WP7 and CK treatments were 5.4, 5.4, 5.3, 4.8, 5.0, 5.4, 5.7 and $5.4 \mathrm{~cm}$, respectively.

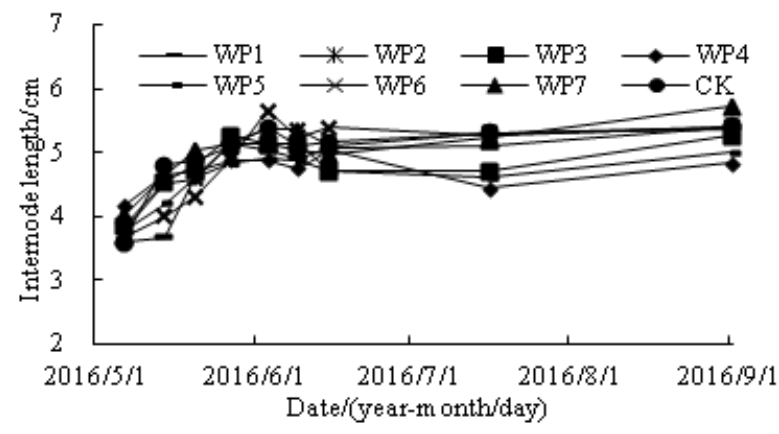

Figure 4. Change in internode length

\section{Change in vine leaves}

Changes in the number of vine leaves under the atomization treatment are shown in Figure 5, which shows that from May 6 to June 15, the number of grape leaves continued to increase and that by Sept. 1, the numbers of leaves under WP1, WP2, WP3, WP4, WP5, WP6, WP7 and CK treatments were 11.0, 15.3, 9.7, 9.5, 8.5, 12.5, 14.0 and 9.5 leaves, respectively.

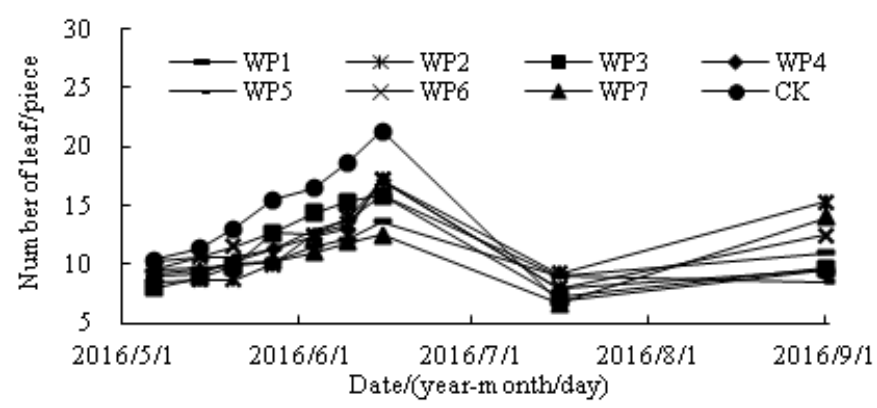

Figure 5. Change in the number of leaves 


\section{Change in the length of vine leaf mid-rib}

Changes in the length of vine leaf mid-ribs under atomization treatment are shown in Figure 6, which shows that from May 6 to May 14, vine leaf mid-ribs grew faster; from May 14 to May 27, vine leaf mid-ribs grew slowly; starting in June, leaves grew rapidly with widely varying changes under different treatments; and by Sept. 1, leaf mid-ribs under various treatments grew relatively slowly and with little variation in growth rates. By Sept. 1, the average lengths of leaf mid-ribs under WP1, WP2, WP3, WP4, WP5, WP6, WP7 and CK treatments were $12.6,12.8,13.2,12.7,11.7,12.9,12.5$ and $12.3 \mathrm{~cm}$, respectively.

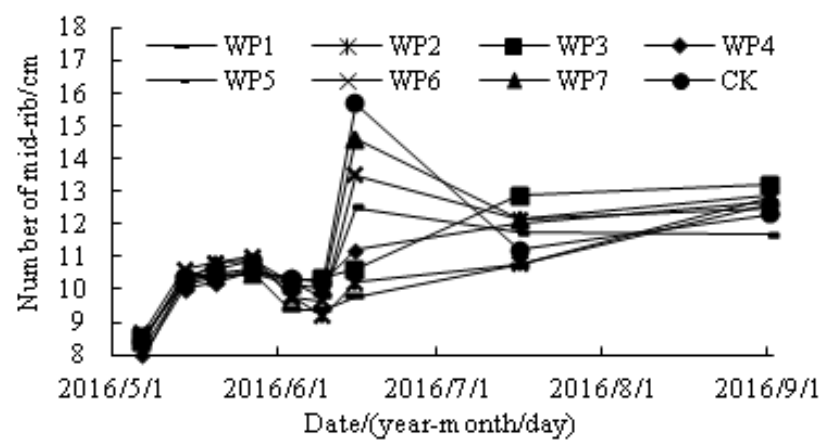

Figure 6. Change in the length of leaf mid-rib

\section{Change in vine branch leaf area}

Changes in vine branch leaf area under atomization treatment are shown in Figure 7. The formula for calculating vine branch leaf area is: leaf area $=1.183 \times \mathrm{X}^{0.456} \times \mathrm{N}$, where $\mathrm{X}$ is the leaf mid-rib length and $\mathrm{N}$ is the number of leaves. By Sept. 1, the average leaf areas under WP1, WP2, WP3, WP4, WP5, WP6, WP7 and CK treatments were 41.1, 58.0, 37.1, $35.8,30.8,47.5,52.4$ and $32.3 \mathrm{~cm}^{2}$, respectively.

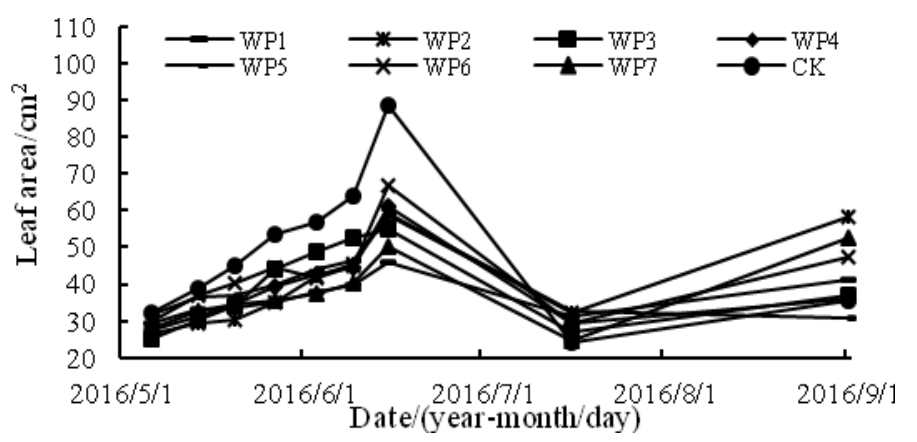

Figure 7. Change in leaf area

\section{Changes in the oven-dry weights of new vine branches}

Oven-dry weights of new vine branches are shown in Figure 8. From the date of initial monitoring, all new vine branches present consistent changes in growth. By Aug. 1, the average oven-dry weights of new branches under WP1, WP2, WP3, WP4, WP5, WP6, WP7 and CK treatments were 17.0, 17.0, 18.5, 17.0, 17.8, 15.8, 17.2 and $15.3 \mathrm{~g}$, respectively. 


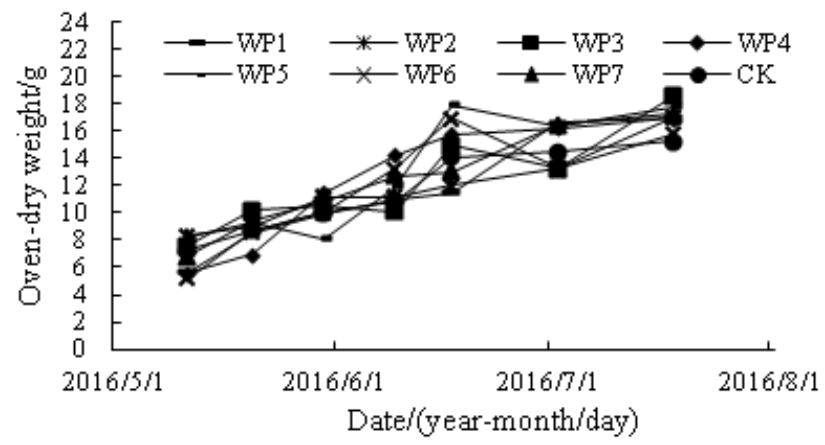

Figure 8. Change in oven-dry weight

\section{Influence of atomizing regulation treatment on changes to grape photosynthesis}

Change in vine leaf photosynthetic rate

The process of daily changes in vine leaf photosynthetic rate under atomization treatment is shown in Figure 9, which shows a consistent law of daily change in photosynthetic rate. Starting at 8:00 am, with a stronger solar radiation intensity and a rising temperature, air holes gradually open, and photosynthetic rates gradually increase until reaching a maximum daily value at 10:00 am. Later in the day, when temperatures continue rising toward the peak daily value, air holes gradually close until they shut off, and photosynthetic rates rapidly drop toward the minimum. At 4:00 pm, when the temperature gradually drops, leaf air holes start to open again, and photosynthetic rates increase once again to reach the second peak daily value. Later in the day, with poorer solar radiation and lower temperatures, photosynthetic rates decrease once again. The law of change under all treatments is consistent, but photosynthetic rates alternate at different time nodes. The average photosynthetic rates under WP1, WP2, WP3, WP4, WP5, WP6, WP7 and CK treatments reach their peak value at 10:00 am, namely, 6.2, $7.2,7.0,8.9,9.2,6.6,6.4$ and $7.2 \mu \mathrm{mol} \mathrm{m} \mathrm{m}^{2}$, respectively, and the average daily photosynthetic rates of the treatments are 5.4, 6.2, 5.7, 6.4, 6.0, 5.5, 5.6, and $6.1 \mu \mathrm{mol} \mathrm{m} \mathrm{s}^{-1}$, respectively.

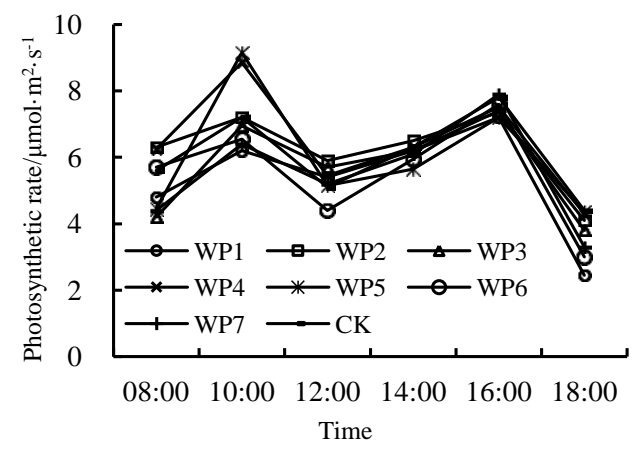

Figure 9. Daily change of leaf's net photosynthetic rate

\section{Change in vine leaf transpiration rate}

Daily changes in leaf transpiration rate under atomization treatment are shown in Figure 10, which demonstrates adherence to the distinctive law of transpiration rate, 
namely, reaching the peak value at approximately 4:00 pm and exhibits a high-low order of WP4 > WP5 > WP3 > WP6 > CK > WP7 > WP2 > WP1.

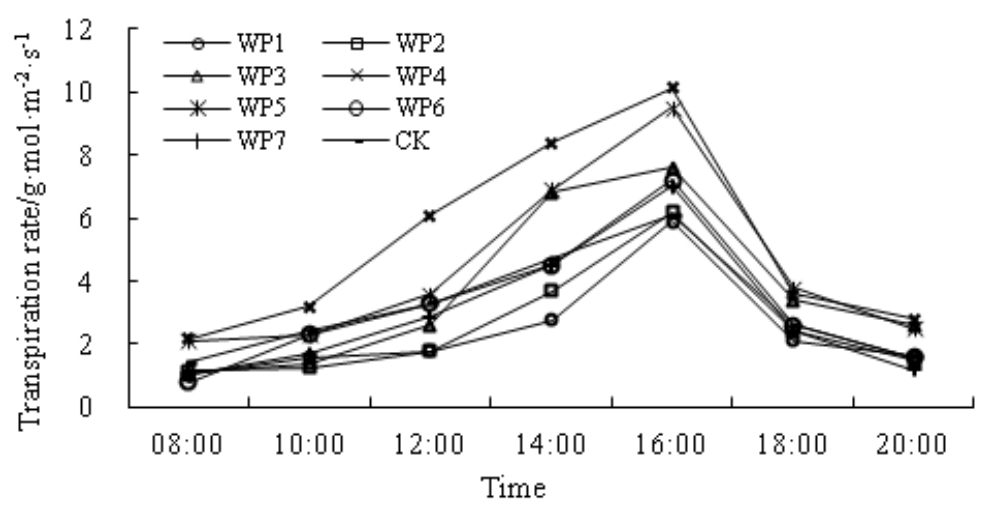

Figure 10. Daily change in leaf transpiration rate

Change in vine leaf air hole conductivity

Daily changes in leaf air holes under atomization treatment are shown in Figure 11, and basic relationships between air hole conductivity are P2 > WP4 > WP3 > WP7 > CK > WP5 > WP1 > WP6. Starting from 8:00 am, vine leaf air hole conductivity continues to increase until reaching the peak value at approximately 12:00 pm as solar radiation intensity becomes stronger and the temperature rises. After that, the conductivity curve of vine leaf air holes continuously drops.

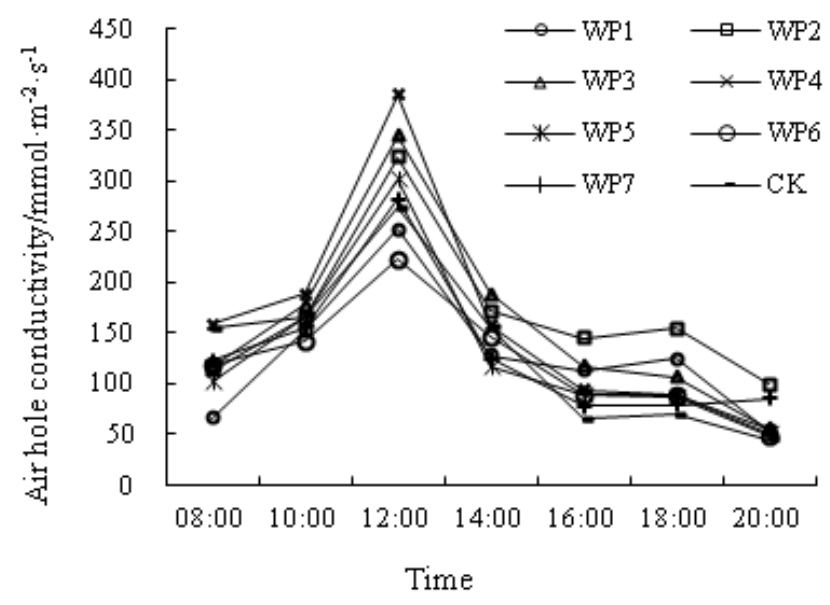

Figure 11. Daily change of leaf air hole conductivity

\section{Influence of atomizing regulation technology on changes in grape photosynthesis characteristics}

Response of grape photosynthetic rate to $\mathrm{CO}_{2}$ concentration

The curve representing grape response to low $\mathrm{CO}_{2}$ concentrations is shown in Figure 12. When $\mathrm{CO}_{2}$ concentrations are under $200 \mu \mathrm{mol} \cdot \mathrm{mol}^{-1}$, the linear equation fits very well, and the coefficient of determination $\left(\mathrm{R}^{2}\right)$ is 0.9773 . 


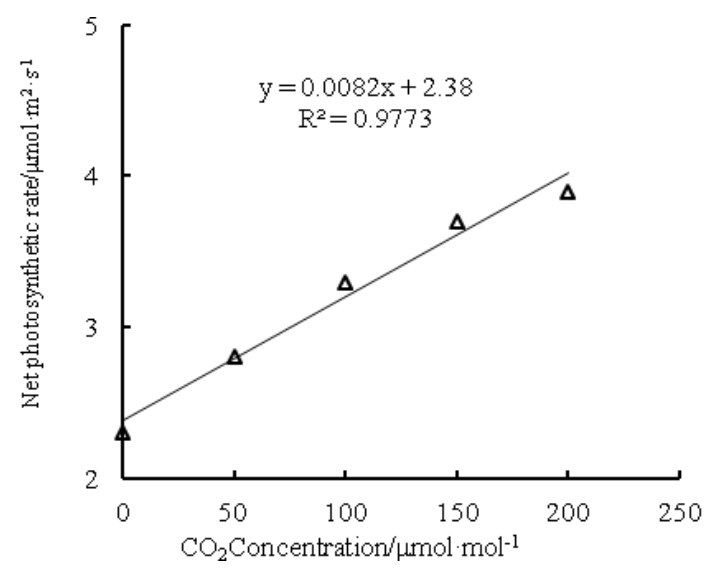

Figure 12. Curve of response to low $\mathrm{CO}_{2}$ concentrations

The curve representing grape response to high $\mathrm{CO}_{2}$ concentrations is shown in Figure 13, which indicates that before $\mathrm{CO}_{2}$ concentrations reach $800 \mu \mathrm{mol} \cdot \mathrm{mol}^{-1}$, photosynthetic rates increase rapidly; after $800 \mu \mathrm{mol} / \mathrm{mol}$, photosynthetic rates increase slowly.

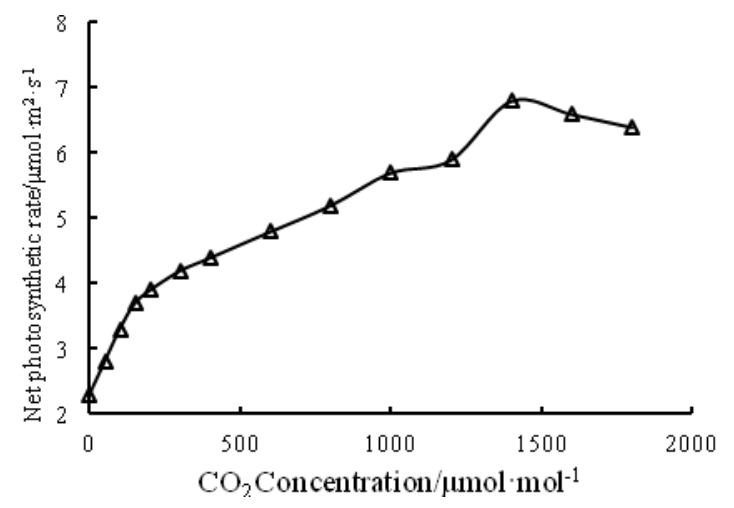

Figure 13. Curve of response to high $\mathrm{CO}_{2}$ concentrations

Using the rectangular hyperbola to fit the curve representing grape response to $\mathrm{CO}_{2}$, we calculate the maximum net photosynthetic rate, the $\mathrm{CO}_{2}$ concentration compensation point and the $\mathrm{CO}_{2}$ concentration saturation point, which are $5.935 \mu \mathrm{mol} \cdot \mathrm{mol}^{-1}$, $351.67 \mu \mathrm{mol} \cdot \mathrm{mol}^{-1}$ and $1175.97 \mu \mathrm{mol} \cdot \mathrm{mol}^{-1}$, respectively. The coefficient of determination is 0.967 , as shown in Table 4.

Table 4. Characteristics of grape $\mathrm{CO}_{2}$ response curve

\begin{tabular}{c|c}
\hline Characteristic parameters of light response & Fitting value \\
\hline Max. photosynthetic rate $\left(\mathrm{A}_{\max }\right) / \mu \mathrm{mol} \cdot \mathrm{m}^{2} \cdot \mathrm{s}^{-1}$ & 5.935 \\
$\mathrm{CO}_{2}$ saturation point $(\mathrm{CSP}) / \mu \mathrm{mol} \cdot \mathrm{mol}^{-1}$ & 1175.97 \\
$\mathrm{CO}_{2}$ compensation point $(\mathrm{CCP}) / \mu \mathrm{mol} \cdot \mathrm{mol}^{-1}$ & 351.67 \\
$\mathrm{Light}$ respiration rate $\left(\mathrm{R}_{\mathrm{p}}\right) / \mu \mathrm{mol} \cdot \mathrm{m}^{2} \cdot \mathrm{s}^{-1}$ & 2.532 \\
Carboxylation efficiency (a) & 0.0072 \\
$\mathrm{R}^{2}$ & 0.967 \\
\hline
\end{tabular}




\section{Response of grape photosynthesis to light intensity}

The curve representing grape photosynthetic response to low light intensity is shown in Figure 14, which indicates that when photosynthetic-effective radiation is under $200 \mu \mathrm{mol} \cdot \mathrm{m}^{-2} \cdot \mathrm{s}^{-1}$, the linear equation fits very well, and the coefficient of determination $\left(\mathrm{R}^{2}\right)$ is 0.9537 .

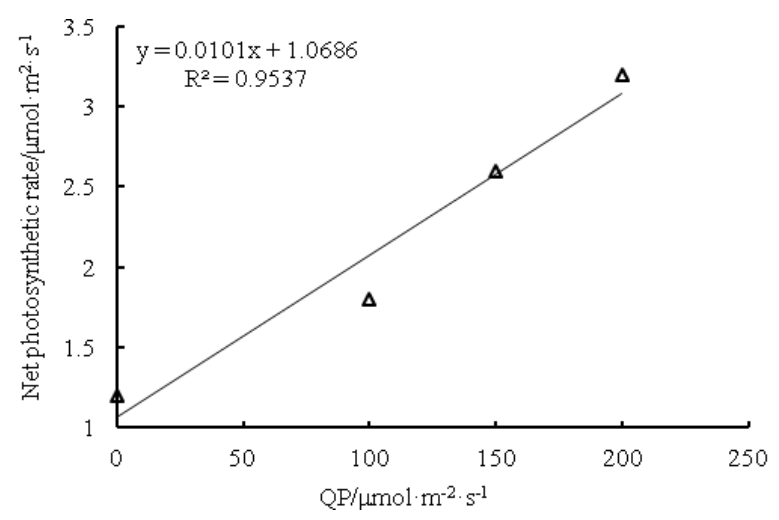

Figure 14. Curve of photosynthetic response to low light intensity

The curve representing grape photosynthetic response to high light intensity is shown in Figure 15, which indicates that when light intensity is $0-600 \mu \mathrm{mol} \cdot \mathrm{m}^{-2} \cdot \mathrm{s}^{-1}$, net photosynthetic rates rise rapidly, increasing with an increase in intensity of illumination. When the intensity of illumination is $600-1500 \mu \mathrm{mol} \cdot \mathrm{m}^{-2} \cdot \mathrm{s}^{-1}$, the rise in net photosynthetic rate is low. When the intensity of illumination is $1500-2000 \mu \mathrm{mol} \cdot \mathrm{m}^{-2} \cdot \mathrm{s}^{-1}$, net photosynthetic rates decrease with an increase in intensity of illumination, demonstrating the light inhibition phenomenon during which the light energy received by a plant leaf exceeds the light quantity that the leaf can utilize. Long time exposure to strong light can lower leaf photosynthetic activity.

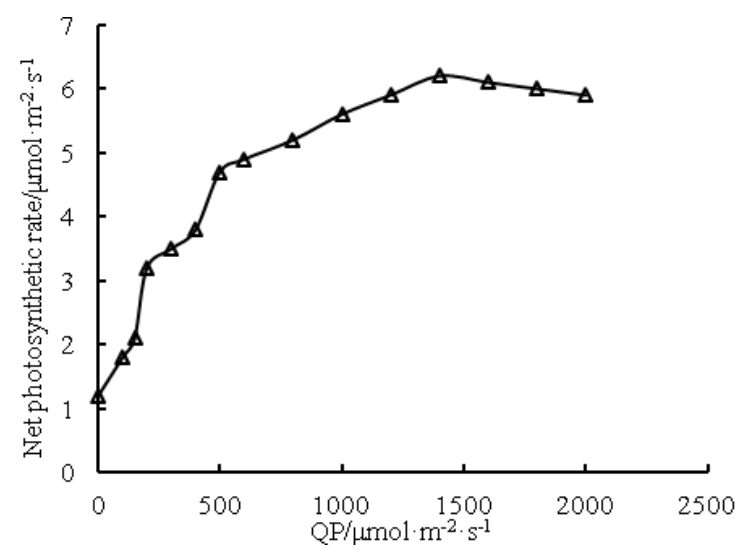

Figure 15. Light intensity response curve

\section{Contrastive analysis of fitted values of grape light response curve models}

The fitted values of the rectangular hyperbola model, as shown in Table 5, show the largest difference from actual measured values, and the net photosynthetic rates of the 
other three models are similar under effective photosynthetic radiation. The fitted values of the corrected rectangular hyperbola model are closest to the actual measured values.

Table 5. Actual measured value and fitted value of light response curve

\begin{tabular}{c|c|c|c|c|c}
\hline & \multicolumn{5}{|c}{ Net photosynthetic rate A $\left(\boldsymbol{\mu m o l} \cdot \mathbf{m}^{\mathbf{2}} \cdot \mathbf{s}^{-\mathbf{1}}\right)$ ) } \\
\hline $\begin{array}{c}\text { Effective photosynthetic } \\
\text { radiation }\left(\boldsymbol{\mu m o l} \cdot \mathbf{m}^{-2} \cdot \mathbf{s}^{-1}\right)\end{array}$ & $\begin{array}{c}\text { Actual } \\
\text { value }\end{array}$ & $\begin{array}{c}\text { Rectangular } \\
\text { hyperbola }\end{array}$ & $\begin{array}{c}\text { Non- } \\
\text { rectangular } \\
\text { hyperbola }\end{array}$ & $\begin{array}{c}\text { Exponential } \\
\text { function }\end{array}$ & $\begin{array}{c}\text { Corrected } \\
\text { rectangular } \\
\text { hyperbola }\end{array}$ \\
\hline 0 & 1.2 & 0.87 & 1.10 & 0.97 & 1.04 \\
50 & 1.5 & 1.55 & 1.54 & 1.52 & 1.55 \\
100 & 1.8 & 2.10 & 1.96 & 2.01 & 2.01 \\
150 & 2.1 & 2.56 & 2.36 & 2.45 & 2.42 \\
200 & 3.2 & 2.94 & 2.75 & 2.84 & 2.80 \\
300 & 3.5 & 3.56 & 3.46 & 3.51 & 3.45 \\
400 & 3.8 & 4.03 & 4.05 & 4.04 & 3.99 \\
500 & 4.7 & 4.40 & 4.53 & 4.47 & 4.44 \\
600 & 4.9 & 4.70 & 4.90 & 4.81 & 4.81 \\
800 & 5.2 & 5.15 & 5.38 & 5.31 & 5.36 \\
1000 & 5.6 & 5.48 & 5.65 & 5.62 & 5.72 \\
1200 & 5.9 & 5.73 & 5.82 & 5.82 & 5.94 \\
1400 & 6.2 & 5.92 & 5.93 & 5.95 & 6.05 \\
1600 & 6.1 & 6.08 & 6.01 & 6.04 & 6.07 \\
1800 & 6 & 6.21 & 6.07 & 6.09 & 6.02 \\
2000 & 5.9 & 6.32 & 6.11 & 6.13 & 5.92 \\
\hline
\end{tabular}

Photosynthetic parameters of the grape light response curve through the fitting of four models are shown in Table 6 . The fitted values of the four light response models are highly correlated with the grape light response curve, of which the non-rectangular hyperbola model and the corrected rectangular hyperbola model have the highest coefficients of determination at 0.988 and 0.989 , respectively. In the rectangular hyperbola model and the non-rectangular hyperbola model, due to their nonconvergence, the light saturation points cannot be obtained but can only be estimated through the linear regression equation under an effective photosynthetic radiation of $200 \mu \mathrm{mol} \cdot \mathrm{m}^{-2} \cdot \mathrm{s}^{-1}$ and a maximum net photosynthetic rate $\left(A_{\max }\right)$. The light saturation points gained in the two models are $544.380 \mu \mathrm{mol} \cdot \mathrm{m}^{-2} \cdot \mathrm{s}^{-1}$ and $501.100 \mu \mathrm{mol} \cdot \mathrm{m}^{-2} \cdot \mathrm{s}^{-1}$, respectively, showing a large difference from the actual measured value of $1400 \mu \mathrm{mol} \cdot \mathrm{m}^{-2} \cdot \mathrm{s}^{-1}$. The exponential function model cannot be obtained because the photosynthetic rate is assumed to be $0.9 A_{\max }$, and the light intensity to which it responds is the saturated light intensity, but the fitted value of $696.80 \mu \mathrm{mol} \cdot \mathrm{m}^{-2} \cdot \mathrm{s}^{-1}$ is far lower than the actual measured value; it is assumed that the light intensity to which the photosynthetic rate responds is $0.99 A_{\max }$. The corrected rectangular hyperbola model can simulate gaining of the light saturation point, with a value of $1557.20 \mu \mathrm{mol} \cdot \mathrm{m}^{-2} \cdot \mathrm{s}^{-1}$, better dealing with the problem of decrease of grape photosynthetic rate in the section of high light intensity, which is closest to the actual measured value. The four models have light compensation points, which is the apparent quantum efficiency and dark respiration rate's simulation value free from significant difference, and the exponential function model's fitted value is closer to the actual measured value; at the highest 
photosynthetic rate, the corrected rectangular hyperbola model's fitted value is $6.072 \mu \mathrm{mol} \cdot \mathrm{m}^{-2} \cdot \mathrm{s}^{-1}$, which is closest to the actual-measured value of $6.1 \mu \mathrm{mol} \cdot \mathrm{m}^{-2} \cdot \mathrm{s}^{-1}$.

Table 6. Photosynthetic parameters of grape light response curve

\begin{tabular}{c|c|c|c|c|c}
\hline $\begin{array}{c}\text { Characteristic } \\
\text { parameters of light } \\
\text { response }\end{array}$ & $\begin{array}{c}\text { Rectangular } \\
\text { hyperbola }\end{array}$ & $\begin{array}{c}\text { Non- } \\
\text { rectangular } \\
\text { hyperbola }\end{array}$ & $\begin{array}{c}\text { Exponential } \\
\text { function }\end{array}$ & $\begin{array}{c}\text { Corrected } \\
\text { rectangular } \\
\text { hyperbola }\end{array}$ & $\begin{array}{c}\text { Actual } \\
\text { measured } \\
\text { value }\end{array}$ \\
\hline $\begin{array}{c}\text { Max photosynthetic rate } \\
\left(\mathrm{A}_{\mathrm{max}}\right) / \mu \mathrm{mol} \cdot \mathrm{m}^{2} \cdot \mathrm{s}^{-1}\end{array}$ & 6.647 & 5.330 & 6.188 & 6.072 & $\approx 6.1$ \\
\hline $\begin{array}{c}\mathrm{Light} \mathrm{saturation} \mathrm{point} \\
(\mathrm{LSP}) / \mu \mathrm{mol} \cdot \mathrm{m}^{-2} \cdot \mathrm{s}^{-1}\end{array}$ & 544.380 & 501.100 & 696.800 & 1557.200 & $\approx 1500$ \\
\hline $\begin{array}{c}\mathrm{Light} \mathrm{compensation} \mathrm{point} \\
(\mathrm{LCP}) / \mu \mathrm{mol} \cdot \mathrm{m}^{-2} \cdot \mathrm{s}^{-1}\end{array}$ & -87.200 & -109.800 & 65.927 & 103.020 & $\approx 90$ \\
\hline $\begin{array}{c}\text { Dark respiration rate } \\
(\mathrm{R} \text { day }) / \mu \mathrm{mol} \cdot \mathrm{m}^{-2} \cdot \mathrm{s}^{-1}\end{array}$ & -0.872 & -1.098 & 0.842 & 1.030 & \\
\hline $\begin{array}{c}\text { Apparent quantum } \\
\text { efficiency }(\psi)\end{array}$ & 0.010 & 0.010 & 0.010 & 0.010 & \\
\hline $\begin{array}{c}\text { Initial quantum } \\
\mathrm{efficiency}(\mathrm{a})\end{array}$ & 0.015 & 0.009 & 0.014 & 0.011 & \\
\hline $\mathrm{R}^{2}$ & 0.980 & 0.988 & 0.987 & 0.989 & \\
\hline
\end{tabular}

\section{Influence of atomizing regulation technology on changes in grape quality and yield}

Grape quality change

Grape quality indicators are shown in Table 7. CK treatment features a total acid content higher than that under all atomization treatments, but the soluble solid content, soluble sugar content, Vc content and sugar acid ratio are all lower than those under the atomization treatments, showing that atomizing regulation technology can effectively improve grape quality.

Table 7. Contrast of grape quality indicators under different treatments

\begin{tabular}{c|c|c|c|c|c}
\hline Treatment & $\begin{array}{c}\text { Soluble solid } \\
\text { content (\%) }\end{array}$ & $\begin{array}{c}\text { Soluble sugar } \\
\text { content (\%) }\end{array}$ & $\begin{array}{c}\text { Total acid } \\
\text { content (\%) }\end{array}$ & $\begin{array}{c}\text { Reduction Vc } \\
\text { content (mg/100 g) }\end{array}$ & $\begin{array}{c}\text { Sugar acid } \\
\text { ratio (\%) }\end{array}$ \\
\hline WP1 & 23.80 & 21.20 & 0.45 & 6.43 & 52.89 \\
WP2 & 24.20 & 22.30 & 0.45 & 6.43 & 53.78 \\
WP3 & 23.00 & 21.00 & 0.45 & 4.29 & 51.11 \\
WP4 & 23.60 & 21.40 & 0.41 & 5.71 & 57.21 \\
WP5 & 22.10 & 20.00 & 0.49 & 2.89 & 45.33 \\
WP6 & 20.20 & 18.10 & 0.45 & 3.86 & 44.89 \\
WP7 & 21.00 & 19.20 & 0.45 & 3.57 & 46.67 \\
WP8 & 19.80 & 17.50 & 0.49 & 2.86 & 40.62 \\
CK & 19.50 & 16.50 & 0.49 & 2.88 & 39.63 \\
\hline
\end{tabular}

\section{Yield change}

Grape yields under atomization treatment are shown in Figure 16, and the average yields under WP1, WP2, WP3, WP4, WP5, WP6, WP7 and CK treatments are 2,829.0, $3,432.7,2,283.0,2,155.5,2,880.8,2,195.8,3,303.9$ and $2767.5 \mathrm{~kg} / \mathrm{hm}^{2}$, respectively. 
Compared with that of CK treatment, yields of the atomization treatments are greater by up to $24.0 \%$, indicating that the atomizing regulation technology plays a clear role in promoting higher yield.

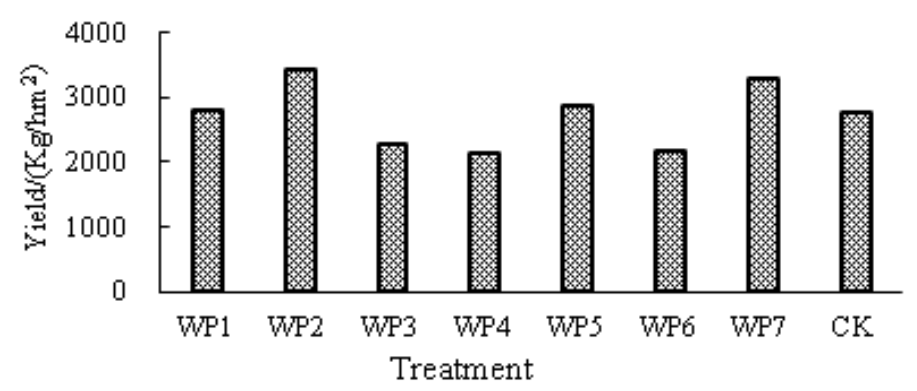

Figure 16. Yield contrast

\section{Discussion}

This study found that sprinkler treatment had lower temperature and higher humidity than control treatment, which was consistent with the results of Hong, et al. (2016). WP5 treatment should have the shortest spraying period and the longest spraying time, the highest air humidity, but the lowest air humidity. This is because the spraying time of WP5 treatment is longer and its physiological development is relatively inhibited, resulting in shorter branch length, shorter internode length, shorter leaf vein length and relatively fewer branches and leaves. The total leaf area of the branches was smaller and the canopy was sparse compared with other treatments, which increased the air exchange between the air and the atmosphere in the canopy, and eventually resulted in the lowest humidity.

The study also found that the net photosynthetic rate of all treatments in the field decreased at 12:00, that is, the phenomenon of "noon break" of crops, which is consistent with the conclusions of Sun et al. (2017), Wang et al. (2015), but the noon break time is earlier than other studies, the reason may be that the temperature in the experimental area is higher than that in other areas. Comparing the fitting models of photosynthetic response curves of different grapes, the fitting values of the right hyperbola model and the measured values have the greatest error, and the fitting values of the modified right hyperbola model are the closest to the measured values. The net photosynthetic rate decreased with the increase of illumination intensity when the illumination intensity ranged from 1500 to 2000 micromol m$~ m^{-2} \mathrm{~s}^{-1}$, which showed the phenomenon of photoinhibition, which was consistent with the results of Bai et al. (2016b).

This study also found that micro-spraying could effectively reduce air temperature and increase humidity in vineyards. The results showed that suitable sprinkler irrigation (WP1, WP2, WP5 and WP7) could improve physiological indexes, photosynthetic characteristics, yield and quality of grapes. Excessive sprinkler irrigation (WP3, WP4 and WP6) could also easily lead to grape yield. Quantity and quality declined. Considering that WP2 treatment is the best treatment among many treatments, but this experiment can only qualitatively screen the best treatment. It is not known how long the spray time (or the amount of spray water) can correspondingly reduce the daily temperature and increase the humidity for grape trees to reach the maximum production capacity under the conditions of temperature and humidity. The numerical value is not clear, so the gradient of sprinkler duration can be set more intensively in future 
experiments. The sprinkler duration is based on the reference crop evapotranspiration on the same day, and is compared with the difference of temperature and humidity in the control group. The yield and quality of each treatment are observed, and the sprinkler duration, temperature and humidity and yield products are discussed. The relationship between quality and yield is to find out the optimal micro-spraying time for maximum yield and quality of grapes.

\section{Conclusions}

Field test research during a growth cycle of grapes under different atomizing regulation treatments indicates that atomizing regulation technology leads to various influences on temperature, humidity, physiological ecology, photosynthetic characteristics, and product quality and quantity. The main conclusions are as follows:

(1) Atomizing regulation technology changes vineyard micro-climates. Research data show that atomizing regulation treatment can lower temperatures by an average of $1.6^{\circ} \mathrm{C}$ during the entire grape expansion period, with a range in temperature drops of up to $5.6 \%$. Average humidity can increase by $6.6 \%$, with the increase range at up to $13.8 \%$, of which WP2 treatment presents the widest range of change. This is very favorable for grape growth and development.

(2) Atomizing regulation technology changes the physiological ecology of grape plants. In terms of branch length, internode length, leaf number and leaf area under all atomization treatments, WP2 and WP7 treatments are most favorable; in terms of midrib length, WP3 and WP6 treatments are most favorable; and in terms of oven-dry weight, WP3 and WP5 treatments are most favorable. All indicators were better than those of CK treatment, demonstrating that regulation technology plays an active role in the physiological ecology of grape plants. In terms of the comprehensive indicator, WP2 treatment presents optimal results.

(3) Atomizing regulation technology slightly influences the photosynthetic characteristics of grapes. Through contrastive analysis of the photosynthetic rate monitoring data, transpiration rates and leaf air hole conductivities of grape plants under various treatments, and fitted calculation analysis of photosynthetic rates, $\mathrm{CO}_{2}$ concentration response curves and light response curves with the "rectangular hyperbola model, non-rectangular hyperbola model, exponential function model and corrected rectangular hyperbola model", it is found that atomizing regulation technology has less influence on the abovementioned items.

(4) Atomizing regulation technology influences grape quality and yield. According to contrastive analysis of grape indicators under various treatments, such as soluble solid content, soluble sugar content, Vc content and sugar acid, those under the atomization treatment are all higher than those under CK treatment. Grapes under WP2 treatment showed optimal quality, indicating that atomizing regulation technology effectively improves grape quality. The atomization treatment that produces the highest yield is WP2 treatment, with a yield of up to $3,432.7 \mathrm{~kg} / \mathrm{hm}^{2}, 24.0 \%$ higher than that from CK treatment.

To summarize the abovementioned research conclusions, WP2 treatment is the optimal technical scheme for atomizing regulation treatment of grapes in extremely arid environments, namely, by erecting micro-spray equipment at $50 \mathrm{~cm}$ under the trellis, with a water spraying diameter of $200 \mathrm{~cm}$ and a spraying cycle of $1 \mathrm{~h} /$ day. In addition, WP2 treatment also shows significant benefits, including water resource conservation, 
creation of a more suitable micro-climate for grape growth, improvements to grape quality and significant yield increase effects.

Acknowledgements. The work was jointly supported by grants from the National Natural Science Foundation of China (51569034, 41371051, 51421006, 41561134016), a key grant of Chinese Academy of Sciences KZZD-EW-12, and a grant from Ministry of Water Resources (201501032).

\section{REFERENCES}

[1] Bai, Y. G., Liu, H. B., Feng, J. (2016a): Research on the influence of micro-spray atomizing regulation irrigation technology on grape physiology and yield. - Chinese Agricultural Science Bulletin 32(19): 164-169.

[2] Bai, Y. G., Liu, H. B., Zhang, J. H., et al. (2016b): Comparison of light-response curve fitted models for grape. - Water Saving Irrigation 9: 8-11.

[3] Chen, Z. Y. (1996): Analysis of agricultural meteorological effect on mulberry field spray irrigation. - Journal of Zhejiang University Sciences Edition 1: 92-99.

[4] Hong, M., Zhao, J. H., Ma, Y. J., et al. (2016): Micro environmental regulation effect of red jujube trees' canopy in arid oasis region. - Agricultural Research in the Arid Areas 34(1): 16-22.

[5] Hui, Z. M., Fang, Y. L., Guo, Y. Z., et al. (2007): Influences of water stress on 4 major physiological indicators of grape seedling. - Agricultural Research in the Arid Areas 25(3): 146-149.

[6] Jackson, J. E. (1970): Aspects of light climate with apple orchards. - Applied Ecol 7: 207-216.

[7] Koblet, W. (1986): Influence of light and temperature on vine performance in cool climates and application to vineyard management. - In: Heatherbell, D. A., Lombard, P. B., Bodyfelt, F. W., Price, S. F. (eds.) Proc Int Symp on Cool Climate. Vitic Enol. Oregon State University, Oregon.

[8] Kohl, K. D., Kohl, R. A., Deboer, D. W. (1987): Measurement of low pressure sprinklers evaporation loss. - Transactions of the AsAE 30(4): 1071-1074.

[9] Liao, X. F., Liu, Q. M., Zhang, D. K., et al. (2012): Model fitting on light response curve of photosynthesis of wild Drepanostachyum luodianense. - Journal of Central South University of Forestry \& Technology 32(3): 124-128.

[10] Liu, H. B., Bai, Y. G., Zhang, J. H., et al. (2019): Effect of water spray duration on SPAD and chlorophyll content of grape leaves. - Chinese Agricultural Science Bulletin 35(12): 107-111.

[11] Liu, H. J., Gong, S. H. (2000): Research on evaporation of water drop in spray irrigation. - Water Saving Irrigation 2: 1620.

[12] Liu, H. J., Kang, Y. H., Wang, Q. G. (2007): Effect of crop canopy on soil water redistribution under sprinkler irrigation: a review. - Agricultural Research in the Arid Areas 2: 137-142.

[13] Society, T. R. (1935): The kinetics of photosynthesis. - Proceedings of the Royal Society of London 149(868): 596-596.

[14] Srinivas, K., Shikhamany, S. D. (2000): Yield and water-use of 'Anab-e-Shahi' grape (Vitis vinifera) vines under drip and basin irrigation. - Indian Journal of Agricultural Science 69(1): 21-23.

[15] Sun, M. S., Li, H., Cheng, P., et al. (2017): Study well type irrigation under different diameter grade prostaglandgray jujube the difference of photosynthetic characteristics. Journal of Central South University of Forestry \& Technology 37(3): 32-38.

[16] Tang, Z., Lv, M., Zhang, X., et al. (2006): Influences of high-temperature stress on three physiological indicators of grape leaf. - Journal of Shihezi University 24(2): 198-200. 
[17] Thornley, J. H. M. (1976): Mathematical Models in Plant Physiology. - Academic Press, London.

[18] Wang, Z. Z., Li, H., Miao, Q. Q., et al. (2015): Photosynthetic characteristics of Chinese jujube under different irrigation conditions in fruit setting period. - Journal of Central South University of Forestry \& Technology 35(5): 59-63+69.

[19] Xie, Q., Shi, L., Du, F., et al. (2007): Influences of $\mathrm{CO}_{2}$ and temperature on grape group photosynthesis. - Journal of Shanghai Jiaotong University 25(2): 110-114.

[20] Xie, Z. (1998): Land-atmosphere coupling mode considering vegetation influences. Chinese Journal of Theoretical and Applied Mechanics 30(3): 267-276.

[21] Ye, Z. P. (2010): A review on modeling of responses of photosynthesis to light and $\mathrm{CO}_{2}$. - Chinese Journal of Plant Ecology 34(6): 727-740.

[22] Zhang, J., Li, Y., Cai, X. (2000): Research on mature biomass of vinifera varieties with different mature periods in Yinchun Region, Ningxia. - Journal of Ningxia Agricultural College 21(1): 10-13. 